\title{
Subject Content-efficacy and Skills Proficiency of Trainee Agriculture Teachers Holding National Certificate in Agriculture, Zimbabwe
}

\author{
Xavier Edziwa ${ }^{1, *} \&$ Andrew Ncube ${ }^{1}$ \\ ${ }^{1}$ Department of Technical Education, University of Zimbabwe, Box MP167, Mt Pleasant, \\ Harare, Zimbabwe \\ *Corresponding author: Department of Technical Education, University of Zimbabwe, Box \\ MP167, Mt Pleasant, Harare, Zimbabwe \\ E-mail: xedziwa@gmail.com or xedziwa@education.uz.ac.zw
}

Received: January 17, 2013 Accepted: March 8, 2013 Published: April 24, 2013

doi:10.5296/ije.v5i2.3066 URL: http://dx.doi.org/10.5296/ije.v5i2.3066

\begin{abstract}
The purpose of the study was to determine the extent to which trainee agriculture teachers, with a National Certificate in Agriculture qualification, were confident in their ability to teach with respect to subject content and practical skills. This was achieved by examining how these trainee teachers perceived their subject content-efficacy and practical skills proficiency related to the Zimbabwe 'O'-Level Agriculture Syllabus 5034. Forty-six trainee agriculture teachers from a technical teachers' college participated in the study. Data was collected using a questionnaire with items weighted on a 5-point Likert scale. Data analysis was done using SPSS Statistics 17.0. The trainee teachers were least efficacious in the laying out of experiments and Agricultural Economics but were rather efficacious in crop science and production. In practicals, trainee teachers were least efficacious in laying out experimental sites and farm machinery but rather efficacious in animal science and crop production.
\end{abstract}

Keywords: content-efficacy; practical skills proficiency; National Certificate in Agriculture 


\section{Introduction}

Agriculture teacher training colleges, in Zimbabwe, used to enrol holders of Diploma in Agriculture, from agricultural colleges, for the Post Agriculture Diploma in Education (PADE) programme. Statistics show that of late the programme has enrolled entirely National Certificate in Agriculture (NCA) (College enrolment files, 2006-2011). Teaching agriculture involves skill and mastery in agriculture content and pedagogical processes associated with managing the total programme of agricultural education. It, therefore, involves the study of technologies and related sciences whilst at the same time puts emphasis on practical skills acquisition. The PADE programme is premised on the understanding that students who are enrolled already have sufficient subject content and requisite skills in conducting practical lessons at 'O'-Level Agriculture teaching. The programme at the teacher's college focuses on pedagogics/methodologies only, with the Department of Teacher Education (DTE) at the University of Zimbabwe (UZ) certifying the pedagogics component only. DTE does not assess the mastery level in the subject content and skills proficiency of the trainee Agriculture teachers i.e. the trainees' subject content knowledge . A need to establish NCA students' content-efficacy and skills proficiency was deemed necessary, by the researchers, as these had become the majority in the Agriculture teacher training programme as opposed to traditional diploma holders.

NCA is a fast track method of training agriculture extension workers that was adopted by the Ministry of Agriculture (MoA) in 2004, on realisation that there was a high farmer to extension worker ratio due to the land reform programme. The MoA was tasked with the training of 6000 extension workers to lower the ratio. All the five conventional agricultural colleges (CACs) and an agricultural institute (AI) had to offer NCA in addition to the diploma they were offering. The NCA programme also saw training of extension workers decentralising at other non-agricultural training centres (Moyo 2004). Trainees needed to have attained any 5 'O'-Levels, irrespective of their school 'O'-Level Agriculture, Mathematics and Science background.

NCA students underwent a 1-2-1 training programme i.e. one term at institution followed by two terms out on attachment and then one term back at institution. This implies that students had a contact time of two terms (approximately 8 months) with their lecturers/tutors. Attachment of students was at government departments preferably extension services and veterinary services. On the contrary, diploma holders underwent a 3-3-3 programme i.e. three terms at college followed by three terms on attachment and then three terms at institution. This translates to six terms (two years) of student-lecturer contact. Attachment of students could be at a government department or private agriculturally biased entities (Chief Agriculture Education Officer, personal communication, May 8, 2012). For the diploma programme, there were follow up mechanisms in which the institution tracked students on attachment to appraise the mentorship each student was getting. On the other hand, NCA students on attachment were assessed by mentors but there were no mechanisms for institutions to make follow up as what prevailed in the diploma programme. The eight months versus two years contact time contrast between NCA and diploma holders raised eyebrows on subject content and skills proficiency of the NCA holders. This pushed the 
researchers to determine the subject content knowledge of NCA holders.

The NCA programme was designed to train 6000 extension staff for Agriculture Research and Extension Services (AREX), Department of Livestock Production and assistants in research stations (Chief Agriculture Education Officer, personal communication, May 8, 2012; Curriculum Development Officer Agriculture Education, personal communication, May 8, 2012). This massive target saw the NCA programme being decentralised from conventional agricultural colleges (CACs) to other non-agricultural training institutions (Muchara, 2010; Moyo, 2004) called vocational training centres (VTCs). Six VTCs were, therefore, incorporated in the training of NCA graduates. According to the Chief Agriculture Education Officer, the VTCs provided facilities for training while the MoA provided personnel to train the students. The VTCs complemented the role of conventional agriculture colleges and agricultural institutes in churning out NCA graduates. This saw the MoA training 6000 workforce in excess, who could not be absorbed by the ministry. By the time this study was carried out, the programme had been phased out in 2010 (Curriculum Development Officer Agriculture Education) but there were approximately 6000 NCA graduates who were yet to be employed. These could continue to be the pool from which the teacher's college would source trainee agriculture teachers.

\subsection{Conceptual Framework}

The success of any teacher to effectively deliver to his/her students greatly depends on the teacher's self efficacy. Johnson and Wardlow (2004) define self-efficacy as an individual's belief in his/her ability to undertake and accomplish a particular task. Bandura (1997) defines self-efficacy as a belief in one's capability to execute the actions necessary to achieve a certain level of performance. Self-efficacy in teaching is an aggregate of personal teaching efficacy, general teaching and content efficacy (Gibson and Dembo, 1984). Content efficacy is the level of confidence a teacher possesses in his/her subject area (Burris, McLaughlin, McCulloch, Brashears and Fraze, 2010). In this text content efficacy refers to an Agriculture teacher's confidence level in the content that is related to the subject. Focus was given to content efficacy because the researchers felt the other components of self-efficacy were catered for by the teacher's college in collaboration with DTE (UZ).

Knowledge in subject matter has been found to be an important characteristic of effective teachers (Roberts \& Dyer, 2004). The subject matter knowledge within agricultural education is complicated in that Agriculture embraces a variety of disciplines. The disciplines include plant and animal physiology, soil science, botany, genetics, agricultural economics and agricultural engineering. In Zimbabwe, an Agricultural teacher is expected to teach all the areas competently in order to fully prepare students for 'O'-Level ZIMSEC examinations and life after school. Furthermore the teacher is expected to guide pupils in conducting field experiments (projects) in their areas of interest, hence the need for knowledge in field experimental lay outs. The project constitutes Paper 3 or coursework for examination purposes.

According to Woolfolk and Hoy (1990), actual teaching experiences during the student teaching practicum have a great impact on personal teaching efficacy and general teaching 
efficacy. However, the researchers' experience was that in Zimbabwe most students went on teaching practicum to schools that generally lacked adequate books for use as reference. Internet sources were also not readily available, therefore, subject content prior to teacher training becomes important given such situation.

\subsection{Statement of the Problem}

An analysis of the training of Agriculture teachers at a teacher's college showed that teaching efficacy and general teaching were taught in pedagogies and teaching practice but little was taught for subject content efficacy and skills proficiency. It was deemed necessary to determine the subject content efficacy of NCA trainee teachers. This study sought to establish the level of confidence of trainee teachers, based on their perceptions, with respect to content and skills in specific areas related to the Zimbabwe 'O'-Level Agriculture Syllabus 5034 .

\subsection{Purpose of the Study}

The purpose of this study was to examine the subject content-efficacy and practical skills proficiency of holders of NCA trainee teachers. In the process the researchers sought to determine pre-service preparation needs, if any, of trainee Agriculture teachers holding NCA.

\subsection{Research Objectives}

- To find out NCA trainee teachers' confidence level with regards to knowledge/ content on key areas of the ' $\mathrm{O}$ ' Level Agriculture syllabus.

- To find out NCA trainee teachers' confidence level with regards to competence in conducting practicals related to key areas of the ' $O$ ' Level Agriculture syllabus.

- To compare trainee teachers' subject content-efficacy by sex/gender, school Agriculture background, category of NCA training, employment status prior to enrolling for teacher training and teaching experience.

\section{Methodology}

\subsection{Research Design}

There was only one college that trained secondary school Agriculture teachers, in Zimbabwe, through its PADE programme. This study was therefore a case study as it focused on this institution only. Each student was asked how she/he perceived her/his subject content-efficacy on given subject areas based on confidence levels. Each participant was also asked how she /he perceived her/his competence to conduct practicals in given subject areas based on confidence levels in her/his skills proficiency.

\subsection{Participants}

All forty-six trainee Agriculture teachers that were in the PADE programme participated in the study. Of the participants, 28 were females and 18 males. All the 46 participants were 
holders of NCA, but having been trained in three categories of institutions set by the researchers as CACs, VTCs and agriculture institutes. CAC refers to those colleges that traditionally train diploma holders. Agricultural institutes refers to colleges that offer farmer training while VTCs refers to non-agricultural centres that were taken aboard to speed up the rate of training the target 6000 work force for extension services.

\subsection{Instrument}

To obtain a quantitative measure of subject content and practical skills proficiency possessed by trainees, 5-point Likert rating scale questionnaires; not confident at all (1) to very confident (5) and not competent at all (1) to very competent (5) were used for confidence in subject content-efficacy and skills proficiency respectively. These rating scales were used as the basis for calculating the mean scores (M) and standard deviation (SD) of the confidence level on each subject content efficacy and practical skill proficiency statement.

Data collection was by means of a questionnaire in a Likert-scale form. A modified Ohio State University (OSU) efficacy scale was used (people.ehe.ohio-state.eduahoyfiles200902tses.pdf). Some modified features of Zarafshani's (2008) efficacy scale were used as well. The questionnaire was divided into four main parts.

The first part solicited for demographic information that included sex, NCA institution attended, school Agriculture background, employment status and teaching experience before enrolling for teacher training. These variables were deemed, by the researchers, to have an influence on participants' confidence level on subject content and skills proficiency. The researchers enquired on participant's sex because agricultural careers have been traditionally male-dominated (Khezerloo \& Breazeale, 2005), hence the need to find out whether sex had no influence on responses given. The second part of the questionnaire sought students' confidence level on the various theory content areas of the Zimbabwe 'O'-Level Agriculture Syllabus 5034. The third part sought students' confidence level on executing practicals in some content areas of that same syllabus. Participants were asked to rate, on a 5-point Likert-scale, how confident they were in the content, listed skills and tasks. The questionnaire was premised on content areas of the Zimbabwe 'O' Level Agriculture Syllabus 5034. The last part of the questionnaire requested students to indicate, if any, content areas they felt needed to be taught at a teacher's college.

\subsection{Data Collection Procedures}

Researchers distributed the questionnaires in person, after clarifying the purpose of the study to students and assuring them that their individual identities and responses would be kept confidential. Participants were also assured that the study would not in anyway affect their study at the college. Questionnaires were completed in the lecture room, in the presence of the researchers. A $100 \%$ return rate was achieved.

\subsection{Data presentation and Analysis}

Data analysis was done using SPSS Statistics 17.0. Mean scores were rounded to the nearest whole number to ease analysis. A whole number scale range of not confident at all (1) 
to very confident (5) was, therefore, used for the level of confidence in subject content. The scale range not competent at all (1) to very competent (5) was used to ascertain practical skills proficiency.

\section{Results}

\subsection{Demographic Characteristics}

Forty-six trainee Agriculture teachers participated in the study (Table 1). Twenty-eight of the participants were female and 18 male. Twenty-six of the participants had school Agriculture background whilst 20 had not done the subject at secondary school level. It was also noted that 29, 14 and 3 participants had done their NCA training at CACs, AI and VTCs respectively. Of these participants 16 were employed as Agriculture teachers after NCA training, 4 as extension workers and 26 were unemployed. For those who were employed as teachers their teaching experiences ranged from 1 year to above 5 years. Twelve had a teaching experience of 1-2 years, 1 had 3-4 years experience and the other 3 above 5 years.

Table 1: Number of participants by sex, 'O'-Level Agriculture background, institution, employment status and teaching experience prior to enrolling at a teacher's college $(\mathrm{N}=46)$

\begin{tabular}{lll}
\hline Gender & Female & 28 \\
& Male & 18 \\
& Total & $\mathbf{4 6}$ \\
\hline Whether did Agriculture at & Yes & 26 \\
'O' Level & No & 20 \\
& Total & $\mathbf{4 6}$ \\
Agriculture institution & CAC & 29 \\
attended & Agricultural Institute & 14 \\
& Vocational Training Centre & 3 \\
Employment prior enrolling & Total & $\mathbf{4 6}$ \\
at a teacher's college & Teacher & 16 \\
& Extension & 4 \\
Teaching experience & Unemployed & 26 \\
& Total & $\mathbf{4 6}$ \\
& 0 years & 30 \\
& $1-2$ years & 12 \\
& 3-4 years & 1 \\
& Above 5 years & 3 \\
& Total & $\mathbf{4 6}$ \\
\hline
\end{tabular}

The demographics show that a majority of the NCA participant Agriculture trainee teachers were from CACs, unemployed and less experienced in teaching. There is need to note here that CACs produced both diploma holders and NCA holders. The diploma holders shunned training as Agriculture teachers. The participants had one thing in common, a NCA qualification, but had trained at different types of institutions. 


\subsection{Participants' Level of Confidence in Content}

The researchers wanted to know the participants' content mastery. Participants were, therefore, asked how confident they were with regards to knowledge of concepts related to a range of subject areas. The results were as portrayed in Table 2.

Table 2: Frequency and mean distribution of students' level of confidence in content in specific subject areas $(\mathrm{N}=46)$

\begin{tabular}{llll}
\hline Level of confidence in content: & N & M & SD \\
\hline Agriculture Economics & 46 & 3.17 & .877 \\
Soil science & 46 & 3.80 & .885 \\
Crop science and production & 46 & 3.93 & .772 \\
Animal science and production & 46 & 3.67 & .896 \\
Farm machinery and mechanisation & 46 & 3.39 & .977 \\
Natural resources management & 46 & 3.63 & .853 \\
Crop irrigation and scheduling & 46 & 3.37 & .878 \\
Layout of experiments & 46 & 2.87 & .806 \\
Writing project report & 46 & 3.35 & .875 \\
Valid N (listwise) & 46 & & \\
\hline
\end{tabular}

Participants expressed, they were somewhat confident (somewhat efficacious) in Agriculture Economics $(\mathrm{M}=3.17$ skewness 0.059), Farm Machinery and Mechanisation $(\mathrm{M}=3.39$ skewness 0.020), Crop Irrigation and Scheduling ( $M=3.37$ skewness 0.212 ) Layout of Experiments ( $\mathrm{M}=2.87$ skewness 0.246$)$ and Writing project report $(\mathrm{M}=3.35$ skewness -0.134$)$. They were confident (efficacious) in Soil Science ( $\mathrm{M}=3.80$ skewness -0.603), Crop Science and Production $(\mathrm{M}=3.93$ skewness -0.492), Animal Science and Production $(\mathrm{M}=3.67$ skewness -0.843), Natural Resources Management ( $M=3.63$ skewness -0.090). It should be noted that there was a negative skewness to means in areas the trainee teachers were efficacious. No participants were 'not confident at all', 'not confident,' or 'very confident' in any content area.

Pearson's Chi-Square tests were conducted to determine whether there were any relationships between participants' confidence levels and their sex, Agriculture background, category of institution attended, employment status prior to enrolling for teacher training and teaching experience. There were no statistical significant relationships between the dependent variable (level of confidence in subject content) and the independent variables listed. This implied that the efficacy levels reflected were not attributable to the independent variables but could, possibly, be due to the NCA programme itself. As Burris et al (2010) put it an individual's content efficacy is determined by the institution and technical agriculture coursework completed (the programme). In this case there was no significant relationship between responses and institution, probably suggesting that the programme (NCA) was the key determinant variable since it was the common independent variable among the trainee teachers. 


\subsection{Participants' Competence in Conducting Practical Tasks in Specific Subject Areas}

The Zimbabwe 'O'-Level Agriculture Syllabus 5034 calls for teachers to conduct practicals related to the theory work students cover and guide students carry out practical projects as a fulfilment of the examination requirement of the subject. The researchers, therefore, asked participants to rate their level of competence in conducting practicals in selected areas (Table 3).

Table 3: Frequency and mean distribution of students' level of competence in conducting practicals in specific subject areas $(\mathrm{N}=46)$

\begin{tabular}{lccc}
\hline Competence level in practicals in & N & M & SD \\
\hline Soil science & 46 & 3.78 & .728 \\
Animal science & 46 & 3.59 & .832 \\
Animal production & 46 & 3.85 & .816 \\
Crop science & 46 & 3.57 & .779 \\
Crop production & 46 & 3.98 & .774 \\
Farm machinery & 46 & 3.33 & .871 \\
Lay out of experimental sites & 46 & 3.11 & .795 \\
Valid N (listwise) & 46 & & \\
\hline
\end{tabular}

Students were asked to rate their ability to conduct practical lessons basing on their NCA knowledge and practical skills. The participants indicated they were 'somewhat competent' in practicals related to Farm Machinery ( $\mathrm{M}=3.33$ skewness 0.353$)$ and Layout of experimental sites $(M=3.11$ skewness 0.077). Participants were 'competent' in practicals related to Soil Science ( $M=3.78$ skewness -0.723), Animal Science $(M=3.59$ skewness 0.195), Animal Production ( $M=3.85$ skewness -0.478), Crop Science ( $M=3.57$ skewness -0.816) and Crop Production ( $\mathrm{M}=3.98$ skewness 0.563$)$. None was 'not competent at all', 'not competent,' or 'very competent'.

Pearson's Chi-Square tests were conducted to determine whether there were any relationships between participants' competence levels in individual subject areas and their sex, Agriculture background, category of institution attended, employment status prior to enrolling for teacher training and teaching experience. There were no significant relationships between the dependent variable (level of competence) and the independent variables listed. This implies that the efficacy levels reflected were not attributable to the independent variables but could, possibly, be due to the programme itself as well.

\subsection{Need for Content Enrichment}

Participants were asked whether there were any subject areas they felt needed to be taught as they went through teacher training. Forty-five participants responded to the question with one absconding. Among those who responded 40 felt there was need for some subject areas to be taught while 5 felt there was no need. 


\section{Macrothink}

Participants were further asked to specify the subject areas they felt be taught to trainee Agriculture teachers at a teacher's college. There was no limit in terms of how many subject areas a participant would list, i.e. participants were free to list as many as they wished. The sum total in Fig 1, showing the responses, therefore exceeded the number of participants. The subject areas were as portrayed in Fig 1.

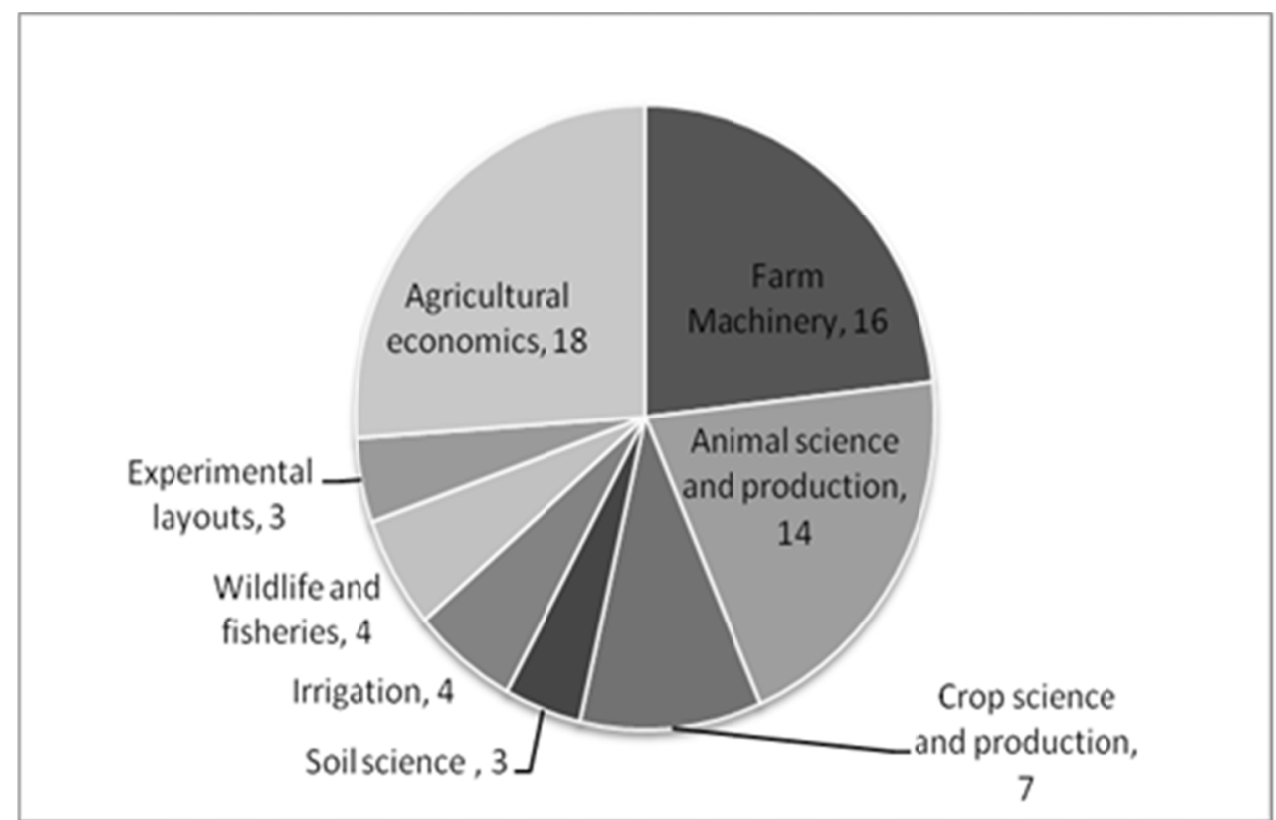

Fig 1: Frequency of subject areas students felt be taught to trainee Agriculture teachers at a teacher's college $(\mathrm{N}=40)$

The most popular subject areas participants felt needed to be taught were Agricultural Economics (18), Farm Machinery (16), Animal Science and Production (14) and Crop Science and Production (7). Some respondents (4) specified Wildlife and Fisheries as an area that requires attention at a teacher's college. Wildlife and Fisheries is a section in Animal Production. This could be signalling a special need. The researchers did not dismiss the notion that may be, the other 14 respondents, who suggested that Amimal Science and Production be taught, could also have been motivated by their deficiencies in Wildlife and Fisheries. A few felt Experimental layouts (3) and Irrigation (4) be taught. This was rather confusing becuase the general reflection on content efficacy had revealed that participants were not that confident in the two areas.

\section{Discussion}

A significant number, 20 out of 46, of the trainee teachers had no Agricultural background from secondary school. Bearing in mind that the duration of NCA is 8-months contact time, one wonders whether the time was adequate enough to introduce a new subject area to a student and make that student an expert in the area. As Olugbenga (2009) puts it, training duration is very crucial as it gives an idea in terms how much a trainee has been moulded for 
a proposed profession or expertise. Many trainee teachers in this study had no pre-service background in the area, one would have expected a programme that enrols such students to be relatively longer so as to ensure their adequate preparation.

With regards to subject content efficacy, the general picture reflected that the trainee teachers were 'somewhat confident' in 5 of the 9 areas under consideration. The fact that the trainee teachers were somewhat confident implies that they were not that efficacious in those areas. This was also reflected by the 40 out of 46 participants who requested there be content enrichment in Agriculture at the teachers' college. Teachers need a high sense of content-efficacy if they are to successfully prepare pupils for national or international examinations (Zarafshani, Knobloch and Aghai, 2008). The Zimbabwe 'O'-Level Agriculture Syllabus 5034 requires an Agriculture teacher to adequately prepare pupils in all disciplines of the syllabus, to pass 'O'-Level. With the trainee teachers expressing doubts in some areas, the key question would be how were those areas going to be taught. Although some authorities (Roberts, Harlin and Ricketts, 2006; Knobloch, 2001; Woolfolk and Hoy, 1990) suggest that content efficacy accrues with experience, no parent would like own child lose out during the time the teacher would be gaining the efficacy. The need for the teacher to be adequately prepared at training level is, therefore, very crucial.

Agriculture as a technical subject requires that the teacher be able to impart practical skills among learners at school. The ability to conduct practicals is important as it has a bearing on pupils' experiential-learning and problem-solving abilities (Roberts, 2006). Participants indicated they were competent in conducting practical tasks in most areas except farm machinery and layout of experimental sites. However, although participants indicated they were competent in other remaining areas, most responses were highly negatively-skewed to the mean score (4) for 'competent'. This also reflects some elements of doubt on the part of participants. It could be deduced that most participants were also somewhat competent, hence not that efficacious.

\section{Conclusions and Recommendations}

This study established that NCA holders lacked in content in some areas of the Agriculture 5034 Syllabus. The trainee teachers expressed deficiencies in Agricultural Economics, Farm Machinery and Experimental layouts. The trainee teachers also expressed doubt in their proficiency in Farm Machinery and Experimental layouts. The suggestion, by the trainee teachers that most areas be taught again at a teacher's college could be indicative enough that more time be devoted in teaching some agricultural concepts in this programme. Basing on the findings and trainee Agriculture teachers' requests the researchers recommend that:

- No NCA holders should follow a one-year PADE programme; the training duration at a teacher's college be extended to allow for content enrichment.

- DTE in conjunction with Department of Technical Education (UZ) should come up with an enrichment programme that is to be certified by DTE. 
- There may be need to revisit the TP duration for NCA holders as most of the trainee Agriculture teachers are no longer from practising teachers only.

\section{References}

Bandura, A. (1997). Self-efficacy: The exercise of control. New York: W. H. Freeman and Company.

Burris, S., McLaughlin, E.K., McCulloch, A., Brashears, T. and Fraze, S. (2010). A Comparison of First and Fifth Year Agriculture Teachers on Personal Teaching Efficacy, General Teaching Efficacy and Content Efficacy. Journal of Agricultural Education, 51(1), 22 - 31. http://dx.doi.org/10.5032/jae.2010.01022

Gibson, S., \& Dembo, M. (1984). Teacher efficacy: a construct validation. Journal of Educational Psychology, 76, 569-582. Retrieved from http://www.jstor.org/stable/1163531

Johnson, D.M., \& Wardlow, G.W. (2004). Computer experience, self-efficacy and knowledge of undergraduate students entering land-grant college of agriculture by year and gender. Journal of Agricultural Education, 45(3), 53-64. http://dx.doi.org/10.5032/jae.2004.03053

Khezerloo, B., \& Breazeale, D. (2005). Educational Needs of Rural Women in the Western-Azarbaijan Province of Iran. Proceedings of the 21st Annual Conference of the Association for International Agricultural and Extension Education, San Antonio, TX.

Knobloch, N.A. (2001). The influence of peer teaching and early field experience on teaching efficacy beliefs of pre-service educators in agriculture. Proceedings of the 28th Annual National Agricultural Education Research Conference, 28, 119-131.

Moyo, S. (2004). 'Farm Sizes, Decongestion and Land Use: Implications of the Fast-Track Land Redistribution Programme in Zimbabwe'. AIAS Monograph Series, Issue No. 2/2004. African Institute for Agrarian Studies.

Muchara, B. (2010). Implications of the fast track land reform programme on markets and market relationships for livestock, cotton and maize products in Mwenezi district of Zimbabwe. Livelihoods after land reform in Zimbabwe. Working Paper 12. Retrieved from http://www.lalr.org.za/zimbabwe/zimbabwe-working-papers-1

Roberts, T.G., Harlin, J.F., \& Ricketts, J.C. (2006). A longitudinal examination of teaching efficacy of agricultural science student teachers. Journal of Agricultural Education, 47(2), 81-92. http://dx.doi.org/10.5032/jae.2006.02081

Roberts, T.G. (2006). A philosophical examination of experiential learning theory for agricultural educators. Journal of Agricultural Education, 4(1), 17-29. http://dx.doi.org/10.5032/jae.2006.01017

Roberts, T. G., \& Dyer, J. E. (2004). Characteristics of effective agriculture teachers. Journal 
of Agricultural Education, 45(4), 65-79. http://dx.doi.org/10.5032/jae.2004.04082

Ohio State University. (2009). Teachers' sense of efficacy scale1 (long form) Retrieved from http://www.people.ehe.osu.edu/ahoy/files/2009/02/tses.pdf

Woolfolk, A. E., \& Hoy, W. K. (1990). Prospective teachers' sense of efficacy and beliefs about control. Journal of educational Psychology, 82, 81-91. http://dx.doi.org/10.1037/0022-0663.82.1.81

Zarafshani, K., Knolbloch, N.A., \& Aghahi, H. (2008). General perceived self-efficacy of Iranian College of Agriculture students. Journal of International Agricultural and Extension Education, 15(1), 69-84. Retrieved from http://www.aiaee.org/attachments/082_Zarafshani-Vol-15.1-7.pdf

\section{Copyright Disclaimer}

Copyright reserved by the author(s).

This article is an open-access article distributed under the terms and conditions of the Creative Commons Attribution license (http://creativecommons.org/licenses/by/3.0/). 